\title{
Burden of childhood diseases and malnutrition in a semi-urban slum in southern India
}

\author{
Rajiv Sarkar ${ }^{1}$, Prabhu Sivarathinaswamy ${ }^{1}$, Bhuvaneshwari Thangaraj ${ }^{1}$, Kulandaipalayam Natarajan Chella Sindhu', \\ Sitara Swarna Rao Ajjampur', Jayaprakash Muliyil ${ }^{2}$, Vinohar Balraj ${ }^{2}$, Elena N Naumova ${ }^{1,3}$, Honorine Ward ${ }^{1,4}$ \\ and Gagandeep Kang ${ }^{1 *}$
}

\begin{abstract}
Background: India has seen rapid unorganized urbanization in the past few decades. However, the burden of childhood diseases and malnutrition in such populations is difficult to quantify. The morbidity experience of children living in semi-urban slums of a southern Indian city is described.
\end{abstract}

Methods: A total of 176 children were recruited pre-weaning from four geographically adjacent, semi-urban slums located in the western outskirts of Vellore, Tamil Nadu for a study on water safety and enteric infections and received either bottled or municipal drinking water based on their area of residence. Children were visited weekly at home and had anthropometry measured monthly until their second birthday.

Results: A total of 3932 episodes of illness were recorded during the follow-up period, resulting in an incidence of 12.5 illnesses/child-year, with more illness during infancy than in the second year of life. Respiratory, mostly upper respiratory infections, and gastrointestinal illnesses were most common. Approximately one-third of children were stunted at two years of age, and two-thirds had at least one episode of growth failure during the two years of follow up. No differences in morbidity were seen between children who received bottled and municipal water.

Conclusions: Our study found a high burden of childhood diseases and malnutrition among urban slum dwellers in southern India. Frequent illnesses may adversely impact children's health and development, besides placing an additional burden on families who need to seek healthcare and find resources to manage illness.

Keywords: Children, Morbidity, Incidence, Slum, Longitudinal study, India

\section{Background}

The UN Millennium Development Goal (MDG) 4 aims to reduce the global under-five mortality rates by twothirds between the years 1990 and 2015 [1]. Although mortality rates have declined globally by about $28 \%$ between 1990 and 2008, about 8.8 million children still die each year before they reach their fifth birthday, with $99 \%$ of these deaths occurring in low and middle income countries [2]. India is the largest contributor, accounting for about one-fifth of the global under-five deaths, totaling approximately 1.8 million child deaths annually [3].

In India, between the years 1991 and 2001, a total of 14.3 million people migrated from rural to urban areas.

\footnotetext{
*Correspondence: gkang@cmcvellore.ac.in

'Department of Gastrointestinal Sciences, Christian Medical College, Vellore, Tamil Nadu 632004, India

Full list of author information is available at the end of the article
}

In cities with populations of over a million, nearly onefourth of the urban population resides in slums [4]. This rapid increase in slum populations poses problems such as poor housing conditions, overcrowding, lack of potable drinking water and sanitation facilities [5], which have a profound effect on human health. People living in slums have a wide range of communicable and noncommunicable diseases [6].

Despite this, the magnitude, distribution and risk factors for the majority of diseases in slum populations are yet to be quantified in many developing countries. In most instances, the information on disease burden and mortality is based on clinic, hospital or national mortality registry data, which represent only the "tip of the iceberg" [7]. Long-term, prospective, population-based surveillance data is required to adequately assess the burden of acute and chronic diseases in such

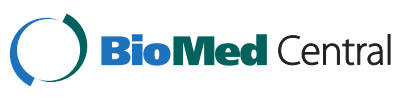


populations and to characterize their determinants. The data obtained through these prospective studies can be used for planning the distribution and utilization of available healthcare resources, and also to develop effective disease control measures.

Here, we present the morbidity experience of children living in semi-urban slums of Vellore in southern India, who participated in a quasi-experimental study on the effect of bottled drinking water on transmission of cryptosporidial infections. A previous birth cohort study conducted between 2002 and 2006 in the same locality had reported a high communicable disease burden among infants and children [8,9]. Widespread contamination of the drinking water supply has also been documented previously [10]. The quasi-experimental design employed in this study allowed us to ascertain whether or not the morbidity patterns differed in children drinking bottled water, in addition to capturing the long-term trends in childhood diseases in this population.

\section{Methods}

\section{Study area and population}

The study was conducted in Ramnaickapalayam, Chinnallapuram, Kaspa and Vasanthapuram, four geographically adjacent, semi-urban slums located in the western outskirts of Vellore, Tamil Nadu, India, with a population of about 40,000, comprising of approximately 50\% Hindu, 45\% Muslim and 5\% Christian households. A large proportion of households use firewood as their primary cooking fuel. "Beedi-work" (manual production of indigenous tobacco-based cigarette-like products) is the predominant occupation, followed by unskilled labor. The majority of household incomes depend on dailywage earners, who do not have the benefit of a regular salary and other benefits such as pension or health insurance. The residents receive piped drinking water, supplied by the local municipality intermittently (at intervals of 2-28 days), which they collect and store in multiple wide-mouthed containers and mostly consume without further treatment [10]. During times of water scarcity, bore-wells located at different parts of the study area and water supplied by the Vellore Municipal Corporation through tank trucks serve as an alternative source of drinking water.

A government urban health centre (UHC), providing free health care to the residents, is located within the study area; and a government teaching hospital is located approximately five $\mathrm{km}$ away. Numerous private facilities, clinics, nursing homes or hospitals and traditional medicine and faith healers are also located in close proximity. The Christian Medical College (CMC), Vellore, a not-for-profit organization and its two outreach units - the Community Health and Development (CHAD) and the Low Cost Effective Care Unit
(LCECU), are located within a few kilometers of the study area.

The UHC records document a birth rate of 15.3 live births per 1000 population per year and an infant mortality rate of 18.2 deaths per 1000 live-births per year for the years 2008-2011. As per the sample registration survey conducted by the Government of India, the birth and infant mortality rates for urban Tamil Nadu for the year 2010 is 15.8 live births per 1000 population and 22 deaths per 1000 live-births respectively [11].

\section{Study design}

A quasi-experimental (non-randomized) study was conducted to determine whether or not a protected water supply could prevent or delay cryptosporidial infections in children under the age of two years. Children were recruited at birth or while they were still being exclusively breast-fed, and their families received either bottled (protected) or municipal (unprotected) drinking water based on their area of residence. The water availability and consumption patterns were, however, similar among residents living in each of these areas, as was the degree of environmental contamination.

The bottled drinking water was obtained from a commercial provider in 20-liter Polyethylene terephthalate (PET) bottles. It is sourced from an underground aquifer and purified by reverse osmosis followed by ultraviolet irradiation and ozonization. The commercial provider follows quality control procedures to ensure that the physical, chemical and microbiological properties of the bottled water meet the specifications of the Bureau of Indian Standards (http://www.bis.org.in/cert/REQUIREMENTSIS14543.htm) (personal communication from the commercial bottled water provider). Prior to start of the study, multiple water samples from the same bottled water provider were independently tested using standard techniques [12], and were found to be free of microbial contamination (presumptive and fecal coliforms).

Supply of bottled water commenced at least one week prior to the scheduled weaning date of the enrolled child or, in case of unscheduled weaning, as soon as the field team became aware of the event. For the purpose of this study, a child was considered to be weaned if he/she were given anything to eat or drink other than breastmilk, including water. Sufficient water was provided for the drinking water needs of the entire household, with households encouraged to call if a replacement was needed ahead of the biweekly scheduled delivery.

\section{Enrollment and data collection}

Prior to enrollment, a door-to-door survey of houses in the study area was conducted to identify families with women in late pregnancy or with children who were being exclusively breast-fed. Those families intending to 
stay in the area for at least two years were approached by the field staff for consent and recruitment. Children with gross congenital anomalies or with birth weight $<1500$ gm were excluded. The study was approved by the Institutional Review Boards at the Christian Medical College, Vellore, India, and the Tufts Medical Center and Tufts University Health Sciences Campus, Boston, USA. Recruitment was consecutive and followed written informed consent by parents or legal guardians of the eligible children. Each child was followed up until he/ she attained the age of two years. The study commenced in September 2008 and ended in April 2011.

Soon after recruitment, field workers visited the house to obtain baseline demographic details and information on water usage and storage, toileting and animal contact. Socio-economic status (SES) of the participating families was also ascertained using a modified version of the Kuppuswamy scale as described previously in the same locality [9]. This composite SES scale takes into account the educational and occupational level of the family, house ownership, total number of rooms in the house (excluding kitchen and bathroom), and household possessions. Based on the above parameters, families received a score ranging from $0-5$. A score of $<2$ denoted low SES.

Household hygiene was measured using a structured questionnaire covering the aspects of water, food and personal hygiene, which has previously been validated and used in the same community $[9,10]$. For this analysis, the hygiene measurement of each child closest to their time of weaning was used. Based on responses to the questionnaire a scoring system was developed and the households were assigned a hygiene score ranging from $0-18$. Families whose scores were at or above the upper tertile $(\geq 12)$ were considered as those with good household hygiene.

Every week, the field staff visited the study household and interviewed the caregiver about diarrhea, vomiting, fever, cold/cough or any other illness experienced by the child during each day since the last visit, using a structured questionnaire. They also enquired about diarrheal and other illnesses in the family, and were trained to use standard definitions to identify common morbidities.

A physician-run clinic was also set up within the study area to provide basic health care to all children under the age of five years in the locality. Primary caregivers were encouraged to bring their sick children to the clinic, and those requiring hospitalization or specialized care were referred to the secondary (CHAD) or tertiary care hospital (CMC), as deemed necessary by the study physician. A record of all such visits was maintained by the field staff. If a child was taken to any other healthcare facility for treatment, the physician recordeddiagnosis in the prescription or discharge summary, if available, was obtained by the field staff during their weekly home visits.

\section{Assessment of malnutrition}

Monthly anthropometric (weight and length/height) measurements were also recorded for all study children. Malnutrition in children was assessed by computing the height-for age (HAZ), weight-for-height (WHZ) and weight-for-age (WAZ) z-scores, using the 2006 WHO child growth standards as the reference population [13]. Based on their $\mathrm{z}$-scores, children were classified as stunted $\left(\mathrm{HAZ}_{<-2} \mathrm{SD}\right)$, wasted $\left(\mathrm{WHZ}_{<-2} \mathrm{SD}\right)$, underweight $\left(\mathrm{WAZ}_{<-2} \mathrm{SD}\right)$ or normal. Any child who was found to be either wasted or underweight was further classified as undernourished. A child was considered to be early and persistently stunted if the HAZ score was $<-2$ SD at 6 months and remained so at 12, 18 and 24 months of age. Similarly, children who were either wasted (WHZ $<-2 \mathrm{SD}$ ) or underweight (WAZ $<-2 \mathrm{SD}$ ) at $6,12,18$ and 24 months were classified as early and persistently undernourished.

\section{Classification of morbidities}

The morbidity experiences of each child, as reported by the primary caregiver or obtained from the discharge summary during the weekly visits were classified into five broad categories - respiratory, gastrointestinal (GI), skin, other infections and non-infectious morbidities. GI illness was defined as diarrhea (3 or more loose watery stools over a $24 \mathrm{~h}$ period [14]) or vomiting lasting for more than $24 \mathrm{~h}$. Respiratory illnesses were classified as either upper (URI) or lower respiratory tract infections (LRI). LRI included bronchitis or pneumonia as diagnosed by a physician, whereas URI included cough, cold and runny nose with and without concomitant symptoms. For URIs without any concomitant symptom, only those lasting for five or more days were considered for analysis. Skin lesions consisted mostly of rashes, but also included a wide variety of other conditions such as vesicles, pustules, cysts, ulcerations and excoriations. Other infections included infections of the eyes, ears or any other localized infection with or without fever. Noninfectious morbidities included non-specific swellings, surgical conditions such as hernia and phimosis, congenital diseases, injuries, insect bites and accidents. For GI morbidities, a new episode was defined as illness occurring at least $48 \mathrm{~h}$ after resolution of the previous episode. For all other illnesses, this time was taken as $72 \mathrm{~h}$.

\section{Statistical analysis}

Data were entered in duplicate using the Epi-Info 2002 (CDC, Atlanta, GA, USA) software and analyzed using STATA 10.1 for Windows (StataCorp, College Station, TX, USA) software. Comparison of baseline differences 
between the bottled and municipal water cohorts was done using $X^{2}$ test or Fisher's exact test for categorical variables and using two-tailed $t$-tests or Wilcoxon rank sum tests for continuous variables, depending on the distribution of data. Incidence rates were calculated as the number of episodes divided by the child-years of follow-up. The total person-time at risk was calculated as total days under surveillance minus days of missing surveillance data (if $\geq 1$ week). In order to account for multiple failures in a child, Poisson survival models with robust standard errors were fitted to calculate the incidence rates for different disease conditions.

\section{Results}

\section{Recruitment and data collection}

The house-to-house survey identified a total of 193 children who fulfilled the eligibility criteria and their families were asked to participate in the study. Of these, 176 (91.2\%) agreed to participate and provided informed consent. Ninety (51.1\%) households of these children received bottled water, whereas the households of 86 (48.9\%) children continued with municipal water usage. The median [inter-quartile range (IQR)] age at the start of follow-up was 22 (12.5-56) days, which was comparable between the two cohorts $(P=0.812)$.
Of the 176 children enrolled into the study, 160 (90.9\%) completed the two-year follow-up. The baseline socio-demographic characteristics of children who were lost to follow-up did not differ significantly from those who remained in the study until the end of follow-up (Table 1). The primary reason for loss to follow-up was migration out of the study area. There was no significant difference in the number of children lost to follow-up between those using bottled or municipal water $(P=0.340)$. Children who dropped out, remained in the study for a median (IQR) period of 14.4 (5.7-17.4) months. The cohort recruitment and follow-up is outlined in Figure 1.

Eliminating periods where per-protocol follow up was not possible because the child was out of the study area, each child was followed-up for a median (IQR) of 22 (20.5-23) months, accounting for a total of 3764 child-months of follow-up. No significant difference in the number of monthly home visits was observed between children drinking bottled and municipal water $(P=0.989)$.

\section{Baseline characteristics}

Overall, children were born mostly into nuclear (83, $47.2 \%)$ or extended $(75,42.6 \%)$ families. The median

Table 1 Comparison of baseline characteristics between children who completed the follow-up and those who were lost to follow-up

\begin{tabular}{|c|c|c|c|}
\hline & $\begin{array}{l}\text { Completed follow-up } \\
(n=160)\end{array}$ & $\begin{array}{l}\text { Lost to follow-up } \\
(n=16)\end{array}$ & $\begin{array}{l}P \text { - } \\
\text { value }\end{array}$ \\
\hline Male child & $85(53.1 \%)$ & $10(62.5 \%)$ & $0.473^{\dagger}$ \\
\hline Nuclear family & $74(46.3 \%)$ & $9(56.3 \%)$ & $0.445^{\dagger}$ \\
\hline Hindu religion & $88(55 \%)$ & $9(56.3 \%)$ & $0.924^{+}$ \\
\hline Median (IQR) birth weight (in kg) * & $2.9(2.6-3.2)$ & $2.9(2.5-3.2)$ & $0.790^{\ddagger}$ \\
\hline Normal vaginal delivery & $139(86.9 \%)$ & $15(93.8 \%)$ & $0.697^{\S}$ \\
\hline Birth in a hospital/health-care facility & $157(98.1 \%)$ & $16(100 \%)$ & $1.000^{\S}$ \\
\hline Median (IQR) age (in months) at introduction of supplementary feeding & $4.7(3.6-5.7)$ & $3.9(2.5-5.4)$ & $0.225^{\neq}$ \\
\hline Median (IQR) family size & $5(4-7)$ & $5(3.5-7)$ & $0.138^{\ddagger}$ \\
\hline Presence of siblings & $111(69.4 \%)$ & $8(50 \%)$ & $0.114^{\dagger}$ \\
\hline Median (IQR) age of the mother (in years) & $24(22-26)$ & $24(21.5-26)$ & $0.967^{\ddagger}$ \\
\hline Median (IQR) years of completed maternal education & $8(3.5-10)$ & $8(6.5-10)$ & $0.243^{\ddagger}$ \\
\hline Median (IQR) years of completed education of the head of the household & $5(0-8)$ & $6.5(2.5-8)$ & $0.277^{\ddagger}$ \\
\hline Presence of cow in the house & $14(18.8 \%)$ & $0(0 \%)$ & $0.370^{\S}$ \\
\hline Presence of any animal in the house & $47(29.4 \%)$ & $3(18.8 \%)$ & $0.562^{\S}$ \\
\hline Living in a "kutcha" house & $31(19.4 \%)$ & $3(18.8 \%)$ & $1.000^{\S}$ \\
\hline Low socio-economic status & $106(66.3 \%)$ & $11(68.8 \%)$ & $0.840^{\dagger}$ \\
\hline Firewood as the primary cooking mode & $83(51.9 \%)$ & $7(43.8 \%)$ & $0.535^{\dagger}$ \\
\hline Presence of a functional toilet within the house $"$ & $98(61.6 \%)$ & $4(66.7 \%)$ & $1.000^{\S}$ \\
\hline Good household hygiene & $44(27.5 \%)$ & $3(18.8 \%)$ & $0.564^{\S}$ \\
\hline
\end{tabular}

* Data missing for 9 children; " Data missing for 11 children.

Tests of significance: ${ }^{+} \mathrm{X}^{2}$ test; ${ }^{\S}$ Fisher's exact test; ${ }^{\ddagger}$ Wilcoxon rank sum test. 


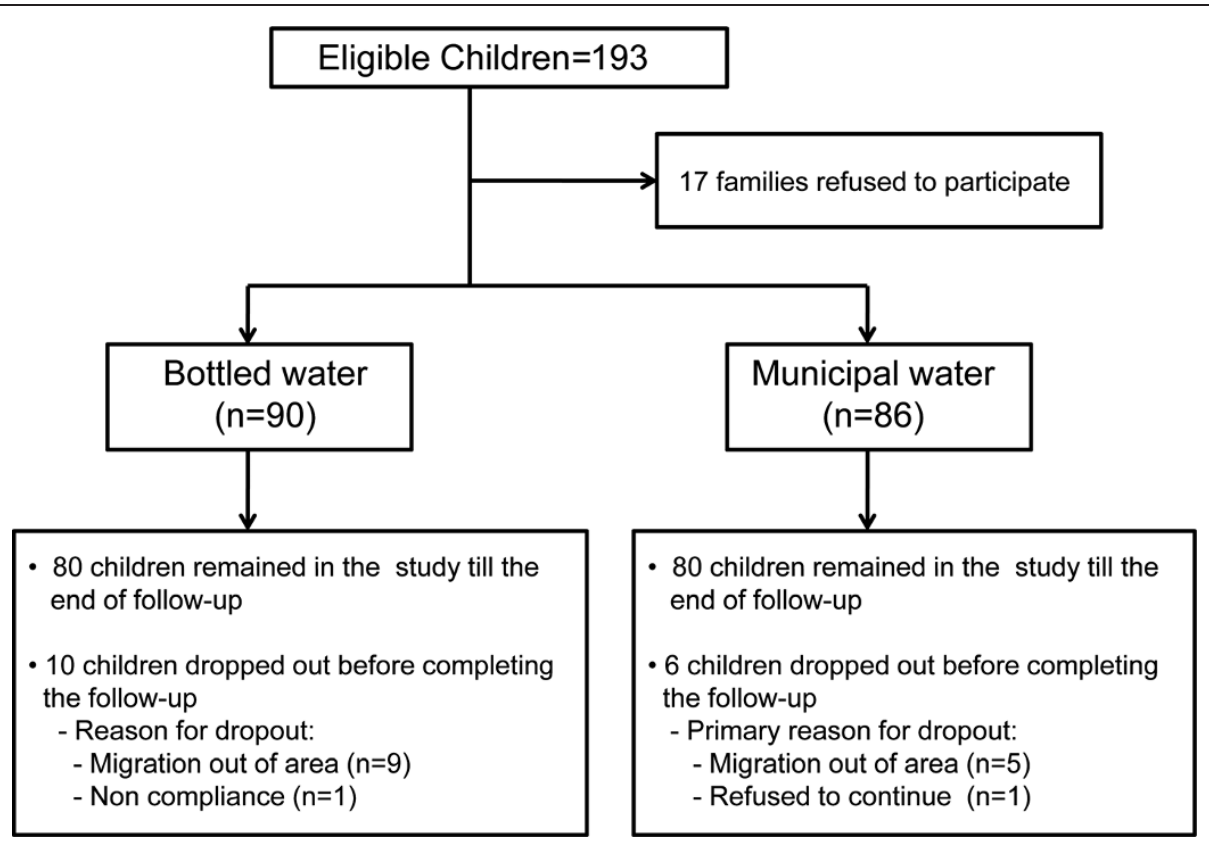

Figure 1 Flowchart of cohort recruitment and follow-up.

(IQR) family size was 5 (4-7) members. The mean (SD) age of the mother at the time of birth of the child was 24.1 (3.4) years, and they had completed a median (IQR) of $8(5-10)$ years of schooling. The majority of the children were Hindus $(97,55.1 \%)$, or Muslims $(70,39.8 \%)$, with only a small proportion of children (9, 5.1\%) belonging to Christian households. Approximately twothirds $(117,66.5 \%)$ of the children belonged to families classified as low socio-economic status. Firewood was the predominant cooking fuel for about half $(90,51.1 \%)$ of the recruited families.

More than half of the children were males $(95,54 \%)$ and over two-thirds $(119,67.6 \%)$ had older siblings. The median age at introduction of supplementary feeding was 4.6 (3.5-5.7) months. For the 167 (94.9\%) children for whom birth weight data was available, mean (SD) weight at birth was $2.9(0.5) \mathrm{kg}$, with 20 (12\%) children classified as low birth weight $(<2.5 \mathrm{~kg})$.

Comparison of baseline characteristics between the bottled and municipal water cohorts (Table 2) revealed certain baseline differences. For example, children provided bottled water weaned earlier and had a smaller family size. Also, a greater proportion of families in the bottled water cohort belonged to the Hindu religion and had poorer household hygiene. On the other hand, significantly more families in the municipal water cohort used firewood as their primary cooking fuel. Compared to those in the municipal water cohort, mothers as well as the head of the households of children in the bottled water cohort had higher levels of education.
Malnutrition among children in the bottled and municipal water cohorts

Complete anthropometric data were available for 161 (91.5\%) of the 176 children under observation. Figure 2 (A and B) presents the proportion (with 95\% CI) of stunted and undernourished (wasted and/or underweight) children at the four different time points $(6,12$, 18 and 24 months of age). Stunting was observed to increase progressively from $14.9 \%$ at 6 months to $30.4 \%$ at 24 months (Figure 2A). On the other hand, prevalence of undernutrition showed an increasing trend between 6 to 18 months of age, decreasing thereafter at 24 months (Figure 2B). The proportions of stunted and undernourished children were comparable between the bottled and municipal water cohorts at each of the four time points.

Twelve (7.5\%) children were found to have early and persistent stunting, whereas 21 (13\%) were persistently undernourished. Seventy (40.5\%) and 85 (52.8\%) children were found to be stunted and undernourished respectively in at least one of the four observations. A total of 101 (62.7\%) children experienced one or more growth failures (stunted/ wasted/underweight) during their follow-up period. When the nutritional parameters were compared between male and female children, no gender differences in the prevalence of either stunting or undernourishment was noticed at any of the four time points.

\section{Morbidity and mortality among children in the bottled and municipal water cohorts}

A total of 3932 episodes of illnesses were recorded during the follow-up period, resulting in an incidence 
Table 2 Comparison of baseline characteristics between children in bottled and municipal water cohorts

\begin{tabular}{|c|c|c|c|}
\hline & $\begin{array}{l}\text { Bottled water } \\
(n=90)\end{array}$ & $\begin{array}{l}\text { Municipal water } \\
(n=86)\end{array}$ & $P$-value \\
\hline Male child & $47(52.1 \%)$ & $48(55.8 \%)$ & $0.633^{\dagger}$ \\
\hline Nuclear family & $43(47.8 \%)$ & $40(46.5 \%)$ & $0.866^{\dagger}$ \\
\hline Hindu religion & $64(71.1 \%)$ & $33(38.4 \%)$ & $<0.001^{\dagger}$ \\
\hline Mean (SD) birth weight (in kg) * & $2.9(0.4)$ & $2.9(0.5)$ & 0.786 \\
\hline Normal vaginal delivery & $77(85.6 \%)$ & $77(89.5 \%)$ & $0.425^{\dagger}$ \\
\hline Birth in a hospital/health-care facility & $89(98.9 \%)$ & $84(97.7 \%)$ & $0.614^{\S}$ \\
\hline Median (IQR) age (in months) at introduction of supplementary feeding & $4.2(3.1-5.1)$ & $5.2(3.8-6.0)$ & $<0.001^{\ddagger}$ \\
\hline Median (IQR) family size & $5(4-7)$ & $6(5-7)$ & $0.043^{\neq}$ \\
\hline Presence of siblings & $56(62.2 \%)$ & $63(73.3 \%)$ & $0.118^{\dagger}$ \\
\hline Mean (SD) age of the mother (in years) & $24.3(3.5)$ & $24.0(3.3)$ & $0.664^{\Delta}$ \\
\hline \multicolumn{4}{|l|}{ Education of the head of the household: } \\
\hline No formal education & $28(31.1 \%)$ & $37(43.0 \%)$ & \multirow[t]{4}{*}{$0.043^{+}$} \\
\hline Up to primary school (5 years) & $14(15.6 \%)$ & $21(24.4 \%)$ & \\
\hline Middle School (6-8 years) & $24(26.7 \%)$ & $16(18.6 \%)$ & \\
\hline High school and above (>8 years) & $24(26.7 \%)$ & $12(14.0 \%)$ & \\
\hline \multicolumn{4}{|l|}{ Education of the mother: } \\
\hline No formal education & $13(14.4 \%)$ & $26(30.2 \%)$ & \multirow[t]{4}{*}{$0.019^{\dagger}$} \\
\hline Up to primary school (5 years) & $11(12.2 \%)$ & $16(18.6 \%)$ & \\
\hline Middle School (6-8 years) & $26(28.9 \%)$ & $20(23.3 \%)$ & \\
\hline High school and above (>8 years) & $40(44.4 \%)$ & $24(27.9 \%)$ & \\
\hline Presence of cow in the house & $6(6.7 \%)$ & $8(9.3 \%)$ & $0.518^{\dagger}$ \\
\hline Presence of any animal in the house & $22(24.4 \%)$ & $28(32.6 \%)$ & $0.233^{\dagger}$ \\
\hline Living in a "kutcha" house & $22(24.4 \%)$ & $12(13.9 \%)$ & $0.078^{\dagger}$ \\
\hline Low socio-economic status & $65(72.2 \%)$ & $52(60.5 \%)$ & $0.099^{\dagger}$ \\
\hline Firewood as the primary cooking mode & $39(43.3 \%)$ & $51(59.3 \%)$ & $0.034^{\dagger}$ \\
\hline Presence of a functional toilet within the house $\$$ & $52(62.7 \%)$ & $50(61.0 \%)$ & $0.825^{\dagger}$ \\
\hline Good household hygiene & $12(13.3 \%)$ & $35(40.7 \%)$ & $<0.001^{\dagger}$ \\
\hline
\end{tabular}

* Data missing for 9 children; " Data missing for 11 children.

Tests of significance: ${ }^{\dagger} \mathrm{X}^{2}$ test; ${ }^{5}$ Fisher's exact test; ${ }^{\ddagger}$ Wilcoxon rank sum test; ${ }^{\Delta}$ two-tailed $t$-test.

(95\% CI) of 12.5 (11.9-13.2) episodes of illness/childyear. There was no significant difference in the overall morbidity pattern between children in the bottled and municipal water cohorts (12.1 episodes/child-year vs. 13.0 episodes/child-year, $P=0.191)$. All except one child reported one or more episodes of illness during the follow-up period.

Children had more illnesses during infancy (13.8 episodes/child-year) than during the subsequent year (11.0 episodes/child-year), irrespective of whether they belonged to the municipal (14.2 vs. 11.6 episodes/ child-year) or bottled water (13.5 vs. 10.4 episodes/ child-year) cohort (Table 3).

Respiratory morbidity was the most common (Figure 3), comprising 60.2\% of all reported morbidities. The incidence $(95 \% \mathrm{CI})$ of respiratory morbidities was calculated at 7.5 (7.2-7.9) episodes/child-year. Children in the municipal water cohort reported significantly more respiratory morbidities (8.3 episodes/child-year) than those in the bottled water cohort (6.8 episodes/ child-year, $P<0.001)$. This difference persisted even after adjusting for the effect of potential confounding variables (Table 4). Almost all respiratory morbidities (98\%) were URIs. The median (IQR) duration of an episode of respiratory illness was 10 (6-21) days, since all uncomplicated URIs of less than 5 days were excluded. On an average, children had an additional 3 episodes of respiratory illness in infancy than during the subsequent year. This trend was similar in children who received bottled and municipal water (Table 3).

GI morbidities accounted for $26.8 \%$ of all reported illnesses (Figure 3), with an incidence (95\% CI) of 

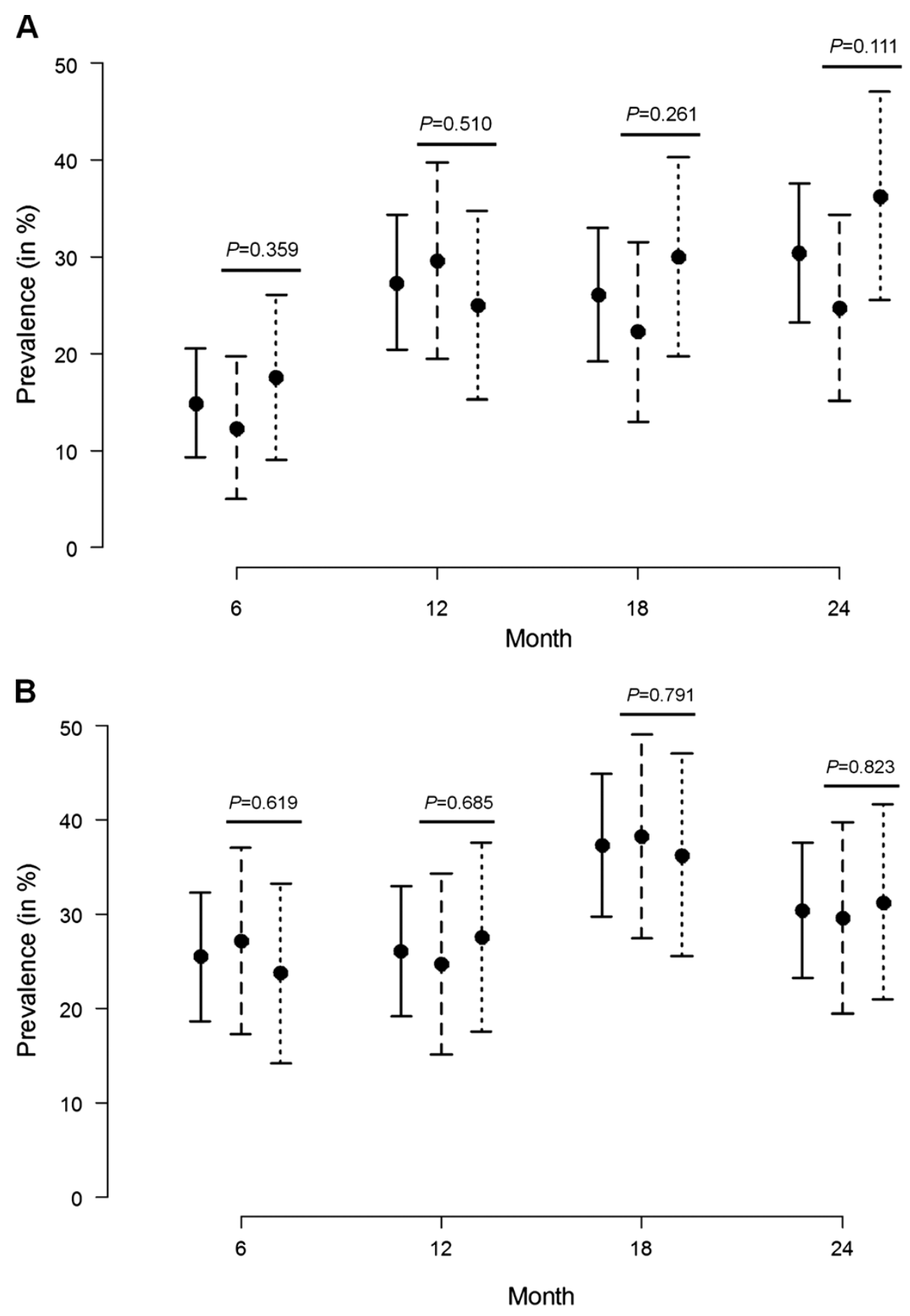

Overall

- - - Bottled water

Municipal water

Figure 2 Prevalence (with $95 \% \mathrm{Cl}$ ) of $(\mathrm{A})$ stunting and (B) undernutrition among the study children at 6, 12, 18 and 24 months of age. The $P$-values represent the results of the comparison of prevalence of nutritional parameters between children in the bottled and municipal water cohorts.

3.4 (3.0-3.8) episodes of GI illness/child-year. The majority of GI morbidities (807 episodes, 76.7\%) were diarrheal episodes (with or without vomiting), followed by vomiting without diarrhea (243 episodes, $23.1 \%)$. The overall diarrheal incidence $(95 \% \mathrm{CI})$ was 2.6 (2.3-2.9) episodes/child-year, whereas that of vomiting was 0.77 (0.63-0.97) episodes/child-year of follow-up.

The incidence of GI morbidities decreased from 4.0 episodes/child-year during infancy to 2.6 episodes/child- 
Table 3 Incidence rates of morbidities and proportion of clinic visits and hospitalizations among children in bottled and municipal water cohorts

\begin{tabular}{|c|c|c|c|c|c|c|c|c|}
\hline & 1st year & & & & 2nd year & & & \\
\hline & Overall & $\begin{array}{l}\text { Bottled } \\
\text { water }\end{array}$ & $\begin{array}{l}\text { Municipal } \\
\text { water }\end{array}$ & $\begin{array}{l}P \text { - } \\
\text { value * }\end{array}$ & Overall & $\begin{array}{l}\text { Bottled } \\
\text { water }\end{array}$ & $\begin{array}{l}\text { Municipal } \\
\text { water }\end{array}$ & $\begin{array}{l}P \text { - } \\
\text { value * }\end{array}$ \\
\hline & $(n=176)$ & $(n=90)$ & $(n=86)$ & & $(n=170)$ & $(n=86)$ & $(n=84)$ & \\
\hline \multicolumn{9}{|l|}{ All-cause morbidities: } \\
\hline No. of episodes & 2331 & 1151 & 1180 & - & 1601 & 767 & 834 & - \\
\hline $\begin{array}{l}\text { Rate of episodes/ } \\
\text { child-year ( } 95 \% \text { Cl) }\end{array}$ & $13.8(13.1-14.7)$ & $13.5(12.4-14.8)$ & $14.2(13.2-15.3)$ & 0.433 & $11.0(10.3-11.8)$ & $10.4(9.3-11.7)$ & $11.6(10.7-12.6)$ & 0.135 \\
\hline $\begin{array}{l}\text { Episodes resulting in clinic } \\
\text { visit: Number (\% of total } \\
\text { illness episodes) }\end{array}$ & $1700(72.9 \%)$ & $847(73.6 \%)$ & $853(72.3 \%)$ & 0.480 & 1089 (68.0\%) & $515(67.1 \%)$ & $574(68.8 \%)$ & 0.472 \\
\hline $\begin{array}{l}\text { Episodes resulting in } \\
\text { hospitalization: Number } \\
\text { (\% of total illness } \\
\text { episodes) }\end{array}$ & $60(2.6 \%)$ & $39(3.4 \%)$ & $21(1.8 \%)$ & 0.014 & $26(1.6 \%)$ & $14(1.8 \%)$ & $12(1.4 \%)$ & 0.541 \\
\hline \multicolumn{9}{|l|}{ Respiratory morbidities: } \\
\hline No. of episodes & 1506 & 693 & 813 & - & 860 & 388 & 472 & - \\
\hline $\begin{array}{l}\text { Rate of episodes/ } \\
\text { child-year ( } 95 \% \text { Cl) }\end{array}$ & $8.9(8.5-9.4)$ & $8.1(7.5-8.8)$ & $9.8(9.1-10.5)$ & 0.001 & $5.9(5.5-6.4)$ & $5.3(4.7-5.9)$ & $6.6(6.0-7.2)$ & 0.003 \\
\hline $\begin{array}{l}\text { Episodes resulting in clinic } \\
\text { visit: Number (\%of total } \\
\text { illness episodes) }\end{array}$ & $1299(86.2 \%)$ & $612(88.3 \%)$ & $687(84.5 \%)$ & 0.032 & $733(85.2 \%)$ & $333(85.8 \%)$ & $400(84.7 \%)$ & 0.657 \\
\hline $\begin{array}{l}\text { Episodes resulting in } \\
\text { hospitalization: Number } \\
\text { (\% of total illness } \\
\text { episodes) }\end{array}$ & $32(2.1 \%)$ & $18(2.6 \%)$ & $14(1.7 \%)$ & 0.240 & $13(1.5 \%)$ & $9(2.3 \%)$ & $4(0.85 \%)$ & 0.078 \\
\hline \multicolumn{9}{|l|}{ GI morbidities: } \\
\hline No. of episodes & 668 & 367 & 301 & - & 384 & 184 & 200 & - \\
\hline $\begin{array}{l}\text { Rate of episodes/ } \\
\text { child-year ( } 95 \% \text { Cl) }\end{array}$ & $4.0(3.5-4.5)$ & $4.3(3.6-5.2)$ & $3.6(3.0-4.3)$ & 0.162 & $2.6(2.3-3.1)$ & $2.5(2.0-3.2)$ & $2.8(2.3-3.4)$ & 0.483 \\
\hline $\begin{array}{l}\text { Episodes resulting in clinic } \\
\text { visit: Number (\% of total } \\
\text { illness episodes) }\end{array}$ & $331(49.6 \%)$ & 197 (53.7\%) & $134(44.5 \%)$ & 0.019 & 197 (51.3\%) & 96 (52.2\%) & $101(50.5 \%)$ & 0.743 \\
\hline $\begin{array}{l}\text { Episodes resulting in } \\
\text { hospitalization: Number } \\
\text { (\% of total illness } \\
\text { episodes) }\end{array}$ & $18(2.7 \%)$ & $12(3.3 \%)$ & $6(2.0 \%)$ & 0.311 & $11(2.9 \%)$ & $5(2.7 \%)$ & $6(3.0 \%)$ & 0.868 \\
\hline \multicolumn{9}{|l|}{ Skin lesions: } \\
\hline No. of episodes & 86 & 47 & 39 & - & 176 & 96 & 80 & - \\
\hline $\begin{array}{l}\text { Rate of episodes/ } \\
\text { child-year ( } 95 \% \text { Cl) }\end{array}$ & $0.51(0.38-0.70)$ & $0.55(0.36-0.89)$ & $0.47(0.33-0.70)$ & 0.574 & $1.2(0.99-1.5)$ & $1.3(0.99-1.8)$ & $1.1(0.8-1.5)$ & 0.449 \\
\hline $\begin{array}{l}\text { Episodes resulting in clinic } \\
\text { visit: Number (\% of total } \\
\text { illness episodes) }\end{array}$ & 34 (39.5\%) & $14(29.8 \%)$ & 20 (51.3\%) & 0.042 & $83(47.2 \%)$ & 45 (46.9\%) & 38 (47.5\%) & 0.934 \\
\hline $\begin{array}{l}\text { Episodes resulting in } \\
\text { hospitalization: Number } \\
\text { (\% of total illness } \\
\text { episodes) }\end{array}$ & $4(4.7 \%)$ & $4(8.5 \%)$ & $0(0 \%)$ & 0.062 & $1(0.57 \%)$ & $0(0 \%)$ & $1(1.3 \%)$ & 0.272 \\
\hline \multicolumn{9}{|l|}{ Other infections: } \\
\hline No. of episodes & 47 & 26 & 21 & - & 88 & 54 & 34 & - \\
\hline \multirow{2}{*}{$\begin{array}{l}\text { Rate of episodes/ } \\
\text { child-year ( } 95 \% \text { Cl) }\end{array}$} & $0.28(0.21-0.38)$ & $0.31(0.21-0.47)$ & $0.25(0.16-0.42)$ & 0.537 & $0.61(0.46-0.81)$ & $0.73(0.51-1.1)$ & $0.47(0.32-0.73)$ & 0.118 \\
\hline & $23(52.3 \%)$ & $13(50 \%)$ & $10(47.6 \%)$ & 0.871 & 34 (38.6\%) & 23 (42.6\%) & 11 (32.4\%) & 0.337 \\
\hline
\end{tabular}


Table 3 Incidence rates of morbidities and proportion of clinic visits and hospitalizations among children in bottled and municipal water cohorts (Continued)

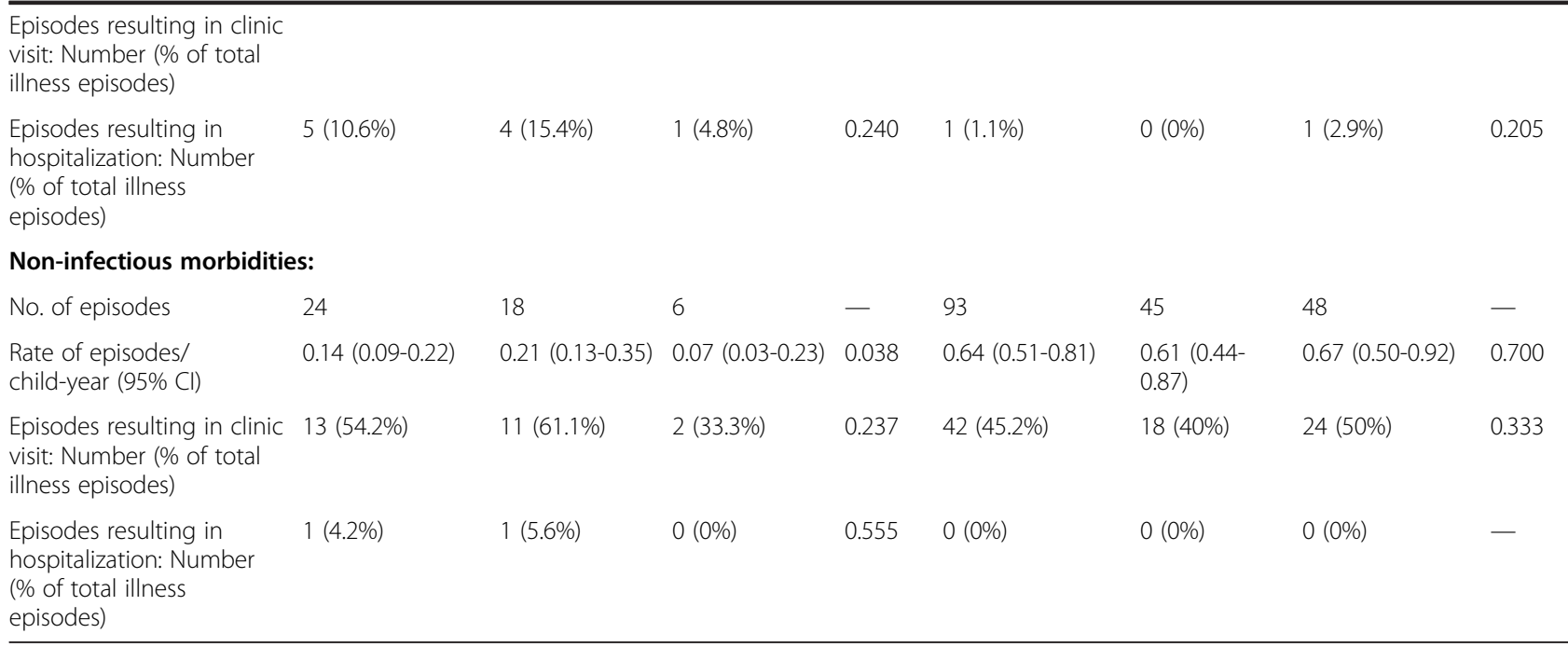

* P-values obtained by comparing the rates in bottled and municipal cohorts using Poisson survival models with robust standard errors.

year during the second year of their life. No difference in the incidence of GI morbidities was noticed between children in the bottled and municipal drinking water cohorts (3.5 episodes/child-year vs. 3.2 episodes/childyear, $P=0.549)$, even after adjusting for potential confounders (Table 4). The median (IQR) duration of an episode of GI morbidity was 3 (2-4) days.

When the diarrheal incidence rates were considered separately for the first two years of life, it was found to decrease from 3.1 episodes/child-year during infancy to 2 episodes/child-year during the second year. This decrease was more noticeable among children drinking bottled water (from 3.3 episodes to 1.8 episodes/childyear) than those drinking municipal water (from 2.8 episodes to 2.2 episodes/child-year), although the overall rates were comparable between children in the two cohorts (2.6 episodes/child-year and 2.5 episodes/childyear respectively, $P=0.654)$.

Incidences of other illnesses ranged from 0.83-0.37 episodes/child-year and were equally distributed between the bottled and municipal water cohorts except for non-infectious morbidities, which was found to be significantly higher during infancy among children using bottled water ( 0.21 episodes/child-year vs. 0.07 episodes/ child year, $P=0.038$ ). However, this difference was not statistically significant in the adjusted analysis (Table 4). In general, the incidence of skin, and other infectious and non-infectious diseases were higher among children during the second year of their life (Table 3). No deaths were reported among the study children.

A large proportion of morbidities (2789/3932, 70.9\%) resulted in clinic or hospital outpatient visits. Among all morbidities reported, healthcare (clinic visit and/or hospitalization) was sought more frequently for respiratory illnesses $(2077 / 2366,87.8 \%)$, followed by gastrointestinal (557/1052, 52.9\%) and non-infectious (56/117, 47.9\%) morbidities (Table 3). Overall, 2.2\% (86/3932) of all morbidities required hospitalization, at a rate of 0.3 (0.2-0.4) hospitalizations/child-year. A greater proportion of gastrointestinal $(29 / 1052,2.8 \%)$ and other infectious diseases $(6 / 135,4.4 \%)$ required hospitalization than respiratory $(45 / 2366,1.9 \%)$, skin $(5 / 262,1.9 \%)$ and noninfectious $(1 / 117,0.8 \%)$ diseases.

\section{Discussion}

Respiratory and diarrheal diseases are two major causes of morbidity and mortality among children residing in the urban slums of India $[8,15]$ and other developing countries $[16,17]$. In our study, respiratory and gastrointestinal illnesses together accounted for $87 \%$ of all childhood morbidities. The overall morbidity burden was high with children suffering from an average of 12.5 episodes of illnesses/year during the first two years of their lives. The findings of our study are comparable to the morbidity experience of children participating in a previous birth cohort study on rotavirus infections between the years 2002 and 2006 in the same slum population (Table 5), where they had an average of 11 episodes of different illnesses/year during the first three years of their lives [8]. However, another study conducted in 1965 among residents of 3 localities in Vellore town had reported a much higher morbidity burden in infants and children, with infants experiencing an average of 17.4 morbidities/child-year of observation (Table 5) [18]. Together, these findings suggest a decreasing trend in the burden of childhood diseases over the years in this 


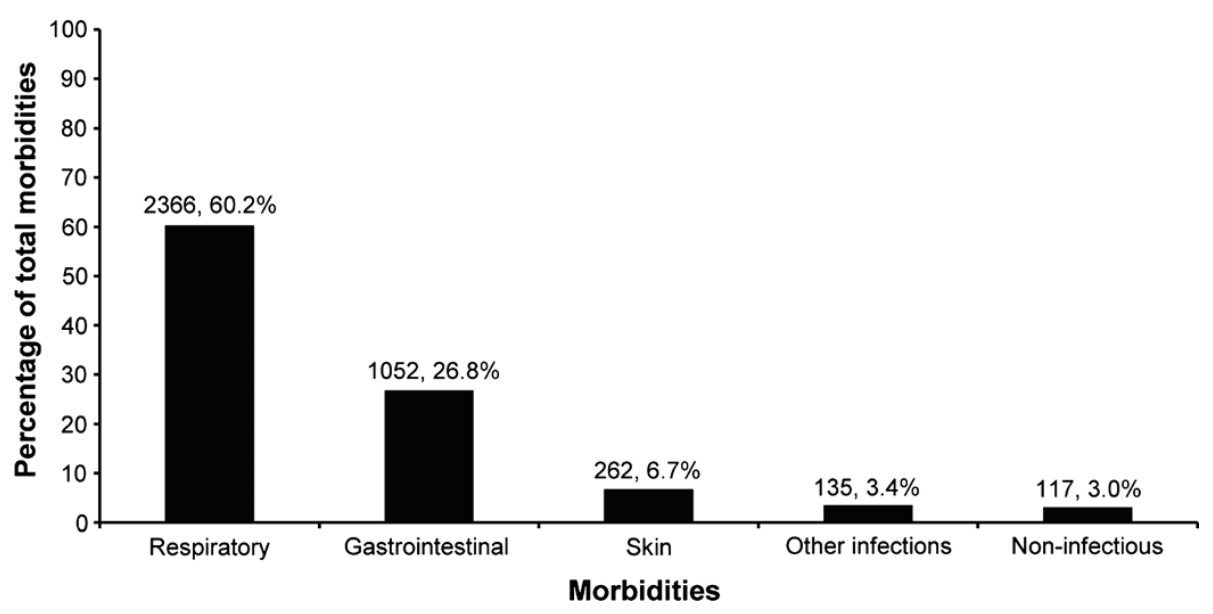

Figure 3 The contribution of different illness categories towards the overall morbidity experience of the study children.

region, possibly due to better access to health care, although the overall disease burden still remains high.

Respiratory illnesses were the commonest cause of morbidity among children in our study, which is in concordance with findings of the previous birth cohort study, in which respiratory illnesses contributed to more than $50 \%$ of the total disease burden [8]. A higher burden of respiratory illnesses has also been reported from longitudinal studies conducted among underprivileged children in Peru [19] and Brazil [16]. The incidence of acute respiratory infections (ARI) among children in developing countries is estimated to range between 12.7 and 16.8 episodes $/ 100$ child-weeks [28], which translates to an annual incidence rate of 6.6-8.8 episodes per child. It is also possible that the high incidence of respiratory illnesses in our study is partly due to the active follow up.

The majority of respiratory illnesses reported in our study were upper respiratory infections, which is in agreement with other prospective studies from developing countries [20-22,29]. The incidence of respiratory morbidities was highest during infancy, decreasing thereafter, which differed from our previous birth cohort study where the incidence of respiratory infections was comparable across the three years of follow-up [8]. A decrease in the incidence of acute respiratory infections (ARI) with increasing age has also been noticed among children in rural Kenya [30]. In general, the rates of ARI seem to peak among infants aged 6-11 months $[18,21,22]$, although higher rates in older children have also been observed [31]. An interesting finding was the significantly higher respiratory morbidity in the municipal drinking water cohort, which is possibly due to the greater use of firewood as the primary cooking fuel among these families (Table 2). The relationship between indoor air pollution from use of solid fuels such as firewood and respiratory illnesses in children has previously been documented [32-34].

GI morbidities were the next most common cause of morbidities among children in our study, almost all of which were episodes of either diarrhea or vomiting (without diarrhea). Taken alone, diarrhea accounted for approximately one-fifth of the overall disease burden. The diarrheal incidence in our study closely resembles

Table 4 Results of unadjusted and adjusted analysis to assess the effect of bottled drinking water on the incidence rates of different morbidities among the study children

\begin{tabular}{|c|c|c|c|c|c|c|c|c|}
\hline \multirow[b]{3}{*}{ Morbidities } & \multicolumn{4}{|l|}{ 1st year $(n=176)$} & \multicolumn{4}{|l|}{ 2nd year $(n=170)$} \\
\hline & \multicolumn{2}{|l|}{ Unadjusted Analysis " } & \multicolumn{2}{|l|}{ Adjusted Analysis *ף } & \multicolumn{2}{|l|}{ Unadjusted Analysis ^ } & \multicolumn{2}{|l|}{ Adjusted Analysis *ף } \\
\hline & Rate Ratio $(95 \% \mathrm{Cl})$ & $P$-value & Rate Ratio $(95 \% \mathrm{Cl})$ & $P$-value & Rate Ratio $(95 \% \mathrm{Cl})$ & $P$-value & Rate Ratio $(95 \% \mathrm{Cl})$ & $P$-value \\
\hline Respiratory & $0.83(0.75-0.92)$ & 0.001 & $0.85(0.75-0.96)$ & 0.007 & $0.80(0.69-0.93)$ & 0.003 & $0.81(0.68-0.96)$ & 0.015 \\
\hline Gastrointestinal & $1.19(0.93-1.53)$ & 0.162 & $1.19(0.87-1.63)$ & 0.271 & $0.90(0.66-1.21)$ & 0.483 & $0.87(0.58-1.31)$ & 0.507 \\
\hline Skin & $1.18(0.66-2.09)$ & 0.574 & $1.52(0.79-2.95)$ & 0.211 & $1.17(0.78-1.76)$ & 0.449 & $0.97(0.63-1.49)$ & 0.878 \\
\hline Other infections & $1.21(0.66-2.22)$ & 0.537 & $0.98(0.51-1.88)$ & 0.949 & $1.55(0.89-2.69)$ & 0.118 & $1.27(0.65-2.50)$ & 0.480 \\
\hline Non-infectious & $2.93(1.06-8.11)$ & 0.038 & $2.80(0.80-9.80)$ & 0.107 & $0.91(0.58-1.44)$ & 0.700 & $0.90(0.53-1.51)$ & 0.687 \\
\hline
\end{tabular}

* Adjusted for: family size, socioeconomic status, use of firewood as the primary cooking fuel, maternal education, presence of toilet at home, Hindu religion, duration of exclusive breast feeding (in months), persistent stunting and household hygiene.

" Rate ratios and $P$-values calculated using Poisson survival models with robust standard errors. 
Table 5 Selected longitudinal studies on morbidities of children residing in urban slums of India and other developing countries, sorted chronologically

\begin{tabular}{|c|c|c|c|c|c|c|c|}
\hline \multirow[t]{2}{*}{ Location } & \multirow[t]{2}{*}{ Year(s) } & \multirow[t]{2}{*}{$\begin{array}{l}\text { Frequency of } \\
\text { surveillance }\end{array}$} & \multirow[t]{2}{*}{$\begin{array}{l}\text { Sample } \\
\text { size }\end{array}$} & \multirow[t]{2}{*}{$\begin{array}{l}\text { Age } \\
\text { group(s) }\end{array}$} & \multicolumn{2}{|l|}{$\begin{array}{l}\text { Measures of } \\
\text { morbidity }\end{array}$} & \multirow[t]{2}{*}{ Ref } \\
\hline & & & & & Type of illness & Frequency & \\
\hline \multirow[t]{6}{*}{ Vellore, India } & $\begin{array}{l}1965- \\
1967\end{array}$ & Twice weekly & $\begin{array}{l}110 \\
\text { families }\end{array}$ & 0-1 year & Total morbidity & Incidence - 17.4 per child-year & [18] \\
\hline & & & & & Respiratory & Incidence - 6.9/child-year & \\
\hline & & & & & Diarrhea & Incidence - 4.7/child-year & \\
\hline & & & & $1-2$ years & Total morbidity & Incidence - 15.4 per child-year & \\
\hline & & & & & Respiratory & Incidence -6.3/child-year & \\
\hline & & & & & Diarrhea & Incidence - 3.4/child-year & \\
\hline \multirow[t]{3}{*}{ Lima, Peru } & $\begin{array}{l}1982- \\
1984\end{array}$ & Thrice weekly & 153 & $\begin{array}{l}0- \\
11 \text { months }\end{array}$ & Diarrhea & Incidence - 9.8/child-year & [19] \\
\hline & & & & & LRI & Incidence - 1.0/child-year & \\
\hline & & & & & Otitis Media & Incidence - 0.8/child-year & \\
\hline \multirow[t]{2}{*}{$\begin{array}{l}\text { Manila, } \\
\text { Philippines }\end{array}$} & $\begin{array}{l}1985- \\
1987\end{array}$ & Weekly & 1978 & $<5$ years & ARI & Incidence - 6.1/child-year & [20] \\
\hline & & & & & LRI & Incidence - 0.5/child-year & \\
\hline \multirow[t]{4}{*}{ Bangkok, Thailand } & $\begin{array}{l}1986- \\
1987\end{array}$ & Twice weekly & 674 & $<5$ years & ARI & Incidence - 11.2/child year & [21] \\
\hline & & & & & mild URI & Incidence - 9/child-year & \\
\hline & & & & & $\begin{array}{l}\text { moderate to severe } \\
\text { URI }\end{array}$ & Incidence - 2.2/child-year & \\
\hline & & & & & LRI & Incidence - 0.07/child-year & \\
\hline \multirow[t]{2}{*}{$\begin{array}{l}\text { Rio de Janeiro, } \\
\text { Brazil }\end{array}$} & $\begin{array}{l}1987- \\
1989\end{array}$ & Weekly & 229 & $<2$ years & ARI & Incidence - 4.5/100 child-weeks & [22] \\
\hline & & & & & LRI & Incidence - 0.8/100 child-weeks & \\
\hline Salvador, Brazil & $\begin{array}{l}1989- \\
1990\end{array}$ & Alternate days & 84 & $<40$ months & Diarrhea & Incidence - 2.8/child-year & [23] \\
\hline Nairobi, Kenya & $\begin{array}{l}1989- \\
1990\end{array}$ & Once every 3 days & 920 & $\begin{array}{l}3- \\
37 \text { months }\end{array}$ & Diarrhea & Incidence - 3.5/child-year & [24] \\
\hline \multirow[t]{4}{*}{ Fortaleza, Brazil } & $\begin{array}{l}1989- \\
1993\end{array}$ & Weekly & 71 & $\begin{array}{l}\text { 6- } \\
21 \text { months }\end{array}$ & ARI & Incidence - 10/child-year & [16] \\
\hline & & & & & Diarrhea & Incidence - 7/child-year & \\
\hline & & & & & Infective dermatitis & Incidence - 1/child-year & \\
\hline & & & & & Respiratory & Prevalence - $15 \%$ & \\
\hline \multirow[t]{3}{*}{ Agartala, India } & $\begin{array}{l}1992- \\
1993\end{array}$ & Twice weekly & 400 & $<5$ years & ARI & $\begin{array}{l}\text { Mean monthly incidence - 23/100 } \\
\text { children }\end{array}$ & [25] \\
\hline & & & & & Diarrhea & Prevalence - $6.3 \%$ & \\
\hline & & & & & Skin disorders & Prevalence - $4.5 \%$ & \\
\hline $\begin{array}{l}\text { Dhaka, } \\
\text { Bangladesh }\end{array}$ & $\begin{array}{l}1999- \\
2002\end{array}$ & Alternate days & 289 & $2-5$ years & Diarrhea & Incidence - 1.8/child-year & [26] \\
\hline \multirow[t]{6}{*}{ Vellore, India } & $\begin{array}{l}2002- \\
2006\end{array}$ & Twice weekly & 452 & $<1$ year & Total morbidity & Incidence - 12.0/child-year & {$[8,9]$} \\
\hline & & & & & Respiratory & Incidence - 7.4/child-year & \\
\hline & & & & & $\mathrm{Gl}$ & Incidence - 3.6/child-year & \\
\hline & & & & $1-2$ years & Total morbidity & Incidence - 11.3/child-year & \\
\hline & & & & & Respiratory & Incidence - 7.1/child-year & \\
\hline & & & & & $\mathrm{Gl}$ & Incidence - 1.6/child-year & \\
\hline
\end{tabular}




\begin{tabular}{|c|c|c|c|c|c|c|c|}
\hline \multirow[t]{3}{*}{ Kiberia, Kenya } & $\begin{array}{l}2006- \\
2008\end{array}$ & $\begin{array}{l}\text { Fortnightly ( } 3 \text { days } \\
\text { recall) }\end{array}$ & 5794 & $<5$ years & ARI & Incidence - 0.5/child-year * & {$[27]$} \\
\hline & & & & & Diarrhea & Incidence $-0.7 /$ child-year * & \\
\hline & & & & & Fever & Incidence - 0.09/child-year * & \\
\hline
\end{tabular}

* Data based on number of clinic visits.

ARI - Acute respiratory infections; URI- Upper respiratory tract infections; LRI - Lower respiratory tract infections; GI - Gastrointestinal morbidities.

the findings from a community-based longitudinal study among children under the age of five years residing in two urban slums of Brazil, where an overall incidence of 2.8 episodes of diarrhea/child/year was reported [23]. However, in another longitudinal study among rural Bangladeshi children, an incidence rate of 1.8 diarrheal episodes/child-year was reported [26], possibly due to the relatively older age (2-5 years) of the children. The morbidity estimates from the global burden of diarrheal disease study among under-five children in developing countries are, however, much higher at 3.2 episodes/ child-year [35]. The temporal and regional difference in the diarrheal incidence (Table 5) thus underscores the need for contemporaneous, region-specific data to accurately estimate the diarrheal disease burden.

Although it was expected that the incidence of GI morbidities will be lower among children drinking bottled water, none of the illness categories other than respiratory illnesses were found to have lower rates. The apparent lack of negative association between bottled water and GI illnesses in our study could be due to contamination of drinking water at the point-of-use. In a study among peri-urban households in Lima, Peru, boiling of water failed to ensure its safety at the end-user level because of contaminated containers and poor domestic hygiene [36]. In the same study, boiled water was found to be more contaminated when served in a drinking cup than when taken directly from a container [36]. Most households in our study poured their drinking water into small, wide-mouthed containers prior to consumption, which were cleaned with locally available water sources that are likely to be contaminated. It has been hypothesized that the contamination of household drinking water may be influenced by several factors such as water storage and handling practices, domestic hygiene and surrounding environment, and social and cultural beliefs and practices [37]; and that improvement of drinking water quality alone might not be sufficient enough to reduce the incidence of diarrhea in places with poor environmental sanitation [38].

In this study the proportions of clinic visits and hospitalizations due to diarrhea and other illnesses were much higher than has previously been reported [27,39]. Although the high rate of clinic visits were expected because the field staff were instructed to encourage caregivers to bring their children to the study clinic whenever they were sick, the high hospitalization rate is possibly a more accurate estimation of the need for disease-related admissions among children residing in Indian slums than current hospitalization rates outside the setting of a study. A similar high rate of hospitalization and low mortality was also observed in the previous birth cohort study [9], which was attributed to good access to health care.

Per the National Family Health Survey 3 (NFHS-3) data, almost half of Indian children under the age of five years are stunted, about 20\% are wasted and about $43 \%$ are underweight [40]. However, community-based studies have found a much higher prevalence of malnutrition among slum children in urban India [41]. In our study too, a large proportion of children were found to have one or more nutritional deficiencies during the followup period. It has been proposed that the high prevalence of childhood malnutrition in Indian slums is mainly due to factors such as inadequate food intake, recurrent illnesses and poor child care practices, as well as other issues such as lack of reach and coordination of public sector services, improper training and supervision of service providers, compromised efficiency of the nutritional programs and inadequate targeting of the urban poor [41].

As with other community-based studies, this study has several limitations. Most of the data on morbidities were collected through reporting by the primary caregiver. This could have resulted in over-reporting of certain morbidities that were perceived to be important by the caregivers and under-reporting of others considered not so important. Additionally, the fact that the children who were never breastfed were excluded from participation might have introduced an inherent selection bias, which in turn, could have resulted in underestimation of the true morbidity burden, since bottle-fed infants tend to have a higher risk of enteric and other infections [42-44]. However, we know from other observational studies in the same area that the proportion of children never breastfed is less than 3\% (unpublished data).

Even though we provided sufficient quantities of bottled drinking water to cover the needs of the entire household by ensuring that water was available on 
demand, it was not possible to monitor or expect complete compliance. It is possible that children drank water from other sources or swallowed untreated water during bathing and other activities. In a recent study from an urban slum in Kolkata, India, it was found that water used for domestic purposes had a higher probability of contamination than that used for drinking purposes [45]. Also, no information was available on the quantity of water utilized for different household activities in our study. Studies have suggested that quantity of water available for domestic use, rather than the quality of source water might be a better predictor of diarrheal disease $[46,47]$. The lack of difference in GI illnesses between the bottled and municipal water cohorts could be explained partially by these limitations or by a high general level of environmental contamination which permits transmission of enteric infections through routes other than drinking water.

\section{Conclusions}

This study demonstrated a continuing high burden of childhood illnesses among urban slum dwellers in southern India. On an average, a child was found to be ill for about three months in a year. In accordance with other studies in impoverished populations, most of the illnesses reported were of infectious origin. Frequent episodes of illness and the high degree of malnutrition experienced by children residing in this and similar settings may adversely impact their health and development, besides placing an additional burden on families who need to seek healthcare and find resources to manage disease. The apparent lack of a protective effect of drinking bottled water necessitates conduct of further studies to assess the effectiveness of alternate strategies, such as improvement of personal and peri-domestic hygiene, in reducing the burden of GI illnesses in settings with high environmental contamination.

\section{Competing interests}

The authors declare that they have no competing interests.

\section{Authors' contributions}

RS coordinated the data collection, carried out the statistical analysis and drafted the manuscript. PS, BT and KNCS assisted with the study coordination and data management. JM, VB and ENN helped with the statistical analysis and in drafting of the manuscript. SSRA and HW participated in the design of the study and provided critical inputs in revising the manuscript. GK conceived the study, participated in its design and coordination and helped to draft and revise the manuscript. All authors read and approved the final manuscript.

\section{Acknowledgements}

We would like to thank Mr. Arumugam, Ms. Hepsi and Ms. Malarkodi for their help with the data collection, and Ms. Sarala and Ms. Sujatha for their help with data entry. We thank Dr. Shobana and the municipal health team for their help with recruitment. We are also indebted to the parents and children of the urban slums of Ramnaickapalayam, Chinnallapuram, Kaspa and Vasanthapuram for their participation and support.
This study was supported by National Institutes of Health grant NIAID R01 A1075452 (GK). RS and SSRA were supported by FIC training grant D43 TW007392 (GK).

\section{Author details}

'Department of Gastrointestinal Sciences, Christian Medical College, Vellore, Tamil Nadu 632004, India. ${ }^{2}$ Community Health Department, Christian Medical College, Vellore, Tamil Nadu 632002, India. ${ }^{3}$ Department of Civil and Environmental Engineering, Tufts University School of Engineering, Medford, MA 02155, USA. ${ }^{4}$ Division of Geographic Medicine and Infectious Diseases, Tufts Medical Center, Tufts University School of Medicine, Boston, MA 02111, USA.

Received: 2 August 2012 Accepted: 27 December 2012

Published: 30 January 2013

\section{References}

1. United Nations Millennium Development Goals. A Gateway to the UN System's Work on the MDGs. http://www.un.org/millenniumgoals/.

2. You D, Wardlaw T, Salama P, Jones G: Levels and trends in under-5 mortality, 1990-2008. Lancet 2010, 375(9709):100-103.

3. Black RE, Cousens S, Johnson HL, Lawn JE, Rudan I, Bassani DG, Jha P, Campbell H, Walker CF, Cibulskis R, et al: Global, regional, and national causes of child mortality in 2008: a systematic analysis. Lancet 2010, 375(9730):1969-1987.

4. Madhiwalla N: Healthcare in urban slums in India. Natl Med J India 2007, 20(3):113-114.

5. UN-Habitat: The Challenge of Slums. Global Report on Human Settlements 2003. London \& Sterling, VA: Earthscan Publications Ltd.; 2003.

6. Sclar ED, Garau P, Carolini G: The 21st century health challenge of slums and cities. Lancet 2005, 365(9462):901-903.

7. Riley LW, Ko Al, Unger A, Reis MG: Slum health: diseases of neglected populations. BMC Int Health Hum Rights 2007, 7:2.

8. Gladstone BP, Das AR, Rehman AM, Jaffar S, Estes MK, Muliyil J, Kang G, Bose A: Burden of illness in the first 3 years of life in an Indian slum. J Trop Pediatr 2010, 56(4):221-226.

9. Gladstone BP, Muliyil JP, Jaffar S, Wheeler JG, Le Fevre A, Iturriza-Gomara M, Gray JJ, Bose A, Estes MK, Brown DW, et al: Infant morbidity in an Indian slum birth cohort. Arch Dis Child 2008, 93(6):479-484.

10. Brick T, Primrose B, Chandrasekhar R, Roy S, Muliyil J, Kang G: Water contamination in urban south India: household storage practices and their implications for water safety and enteric infections. Int J Hyg Environ Health 2004, 207(5):473-480.

11. Registrar General, India: Sample registration system. Estimated birth rate, death rate, natural growth rate and infant mortality rate, 2010. SRS Bulletin 2011, 46(1):1-6.

12. Senior BW: Examination of water, milk, food and air. In Practical Medical Microbiology. 13th edition. Edited by Collee JG, Duguid JP, Fraser AG, Marmion BP. Edinburgh: Churchill Livingstone; 1989:204-213.

13. WHO: WHO Child Growth Standards: Length/Height-for-Age, Weight-for-Age, Weight-for-Length, Weight-for-Height and Body Mass Index-for-Age: Methods and Development. Geneva: World Health Organization; 2006.

14. Morris SS, Cousens SN, Lanata CF, Kirkwood BR: Diarrhoea-defining the episode. Int J Epidemiol 1994, 23(3):617-623.

15. Awasthi S, Agarwal S: Determinants of childhood mortality and morbidity in urban slums in India. Indian Pediatr 2003, 40(12):1145-1161.

16. Castro MX, Soares AM, Fonseca W, Rey LC, Guerrant RL, Lima AA: Common infectious diseases and skin test anergy in children from an urban slum in northeast Brazil. Braz J Infect Dis 2003, 7(6):387-394.

17. Hussain A, Ali SM, Kvale G: Determinants of mortality among children in the urban slums of Dhaka city, Bangladesh. Trop Med Int Health 1999, 4(11):758-764.

18. Kamath KR, Feldman RA, Rao PS, Webb JK: Infection and disease in a group of South India families. II. General morbidity patterns in families and family members. Am J Epidemiol 1969, 89(4):375-383.

19. Lopez De Romana G, Brown KH, Black RE, Kanashiro HC: Longitudinal studies of infectious diseases and physical growth of infants in Huascar an underprivileged peri-urban community in Lima, Peru. Am J Epidemiol 1989, 129(4):769-784.

20. Tupasi TE, de Leon LE, Lupisan S, Torres CU, Leonor ZA, Sunico ES, Mangubat NV, Miguel CA, Medalla F, Tan ST, et al: Patterns of acute 
respiratory tract infection in children: a longitudinal study in a depressed community in Metro Manila. Rev Infect Dis 1990, 12(Suppl 8):S940-S949.

21. Vathanophas K, Sangchai R, Raktham S, Pariyanonda A, Thangsuvan J, Bunyaratabhandu P, Athipanyakom S, Suwanjutha S, Jayanetra P, Wasi C, et al: A community-based study of acute respiratory tract infection in Thai children. Rev Infect Dis 1990, 12(Suppl 8):S957-S965.

22. Sutmoller F, Maia PR: Acute respiratory infections in children living in two low income communities of Rio de Janeiro, Brazil. Mem Inst Oswaldo Cruz 1995, 90(6):665-674.

23. Melo MC, Taddei JA, Diniz-Santos DR, Vieira C, Carneiro NB, Melo RF, Silva LR: Incidence of diarrhea in children living in urban slums in Salvador, Brazil. Braz J Infect Dis 2008, 12(1):89-93.

24. Mirza NM, Caulfield LE, Black RE, Macharia WM: Risk factors for diarrheal duration. Am J Epidemiol 1997, 146(9):776-785.

25. Deb SK: Acute respiratory disease survey in Tripura in case of children below five years of age. J Indian Med Assoc 1998, 96(4):111-116.

26. Haque R, Mondal D, Kirkpatrick BD, Akther S, Farr BM, Sack RB, Petri WA Jr: Epidemiologic and clinical characteristics of acute diarrhea with emphasis on Entamoeba histolytica infections in preschool children in an urban slum of Dhaka, Bangladesh. Am J Trop Med Hyg 2003, 69(4):398-405.

27. Feikin DR, Olack B, Bigogo GM, Audi A, Cosmas L, Aura B, Burke $H$, Njenga MK, Williamson J, Breiman RF: The burden of common infectious disease syndromes at the clinic and household level from population-based surveillance in rural and urban Kenya. PLoS One 2011, 6(1):e16085.

28. Selwyn BJ: The epidemiology of acute respiratory tract infection in young children: comparison of findings from several developing countries. Coordinated Data Group of BOSTID Researchers. Rev Infect Dis 1990, 12(Suppl 8):S870-S888.

29. Broor S, Parveen S, Bharaj P, Prasad VS, Srinivasulu KN, Sumanth KM, Kapoor SK, Fowler K, Sullender WM: A prospective three-year cohort study of the epidemiology and virology of acute respiratory infections of children in rural India. PLoS One 2007, 2(6):e491.

30. Wafula EM, Onyango FE, Mirza WM, Macharia WM, Wamola I, Ndinya-Achola JO, Agwanda R, Waigwa RN, Musia J: Epidemiology of acute respiratory tract infections among young children in Kenya. Rev Infect Dis 1990, 12(Suppl 8):S1035-S1038.

31. Zaman K, Baqui AH, Yunus M, Sack RB, Bateman OM, Chowdhury HR, Black RE: Acute respiratory infections in children: a communitybased longitudinal study in rural Bangladesh. J Trop Pediatr 1997, 43(3):133-137.

32. Dherani M, Pope D, Mascarenhas M, Smith KR, Weber M, Bruce N: Indoor air pollution from unprocessed solid fuel use and pneumonia risk in children aged under five years: a systematic review and meta-analysis. Bull World Health Organ 2008, 86(5):390-398C.

33. Pandey MR, Neupane RP, Gautam A, Shrestha IB: Domestic smoke pollution and acute respiratory infections in a rural community of the hill region of Nepal. Environ Int 1989, 15(1-6):337-340.

34. Riojas-Rodriguez H, Romano-Riquer P, Santos-Burgoa C, Smith KR: Household firewood use and the health of children and women of Indian communities in Chiapas, Mexico. Int J Occup Environ Health 2001, 7(1):44-53.

35. Kosek M, Bern C, Guerrant RL: The global burden of diarrhoeal disease, as estimated from studies published between 1992 and 2000. Bull World Health Organ 2003, 81(3):197-204.

36. Oswald WE, Lescano AG, Bern C, Calderon MM, Cabrera L, Gilman RH: Fecal contamination of drinking water within peri-urban households, Lima, Peru. Am J Trop Med Hyg 2007, 77(4):699-704.

37. Trevett AF, Carter RC, Tyrrel SF: The importance of domestic water quality management in the context of faecal-oral disease transmission. J Water Health 2005, 3(3):259-270.

38. VanDerslice J, Briscoe J: Environmental interventions in developing countries: interactions and their implications. Am J Epidemiol 1995, 141(2):135-144.

39. Parashar UD, Hummelman EG, Bresee JS, Miller MA, Glass Rl: Global illness and deaths caused by rotavirus disease in children. Emerg Infect Dis 2003, 9(5):565-572.

40. Indian Institute of Population Survey (IIPS) and Macro International: National Family Health Survey (NFHS-3), 2005-06: India. Volume 1. Mumbai: IIPS; 2007.
41. Ghosh S, Shah D: Nutritional problems in urban slum children. Indian Pediatr 2004, 41(7):682-696.

42. Duijts $L$, Jaddoe WW, Hofman A, Moll HA: Prolonged and exclusive breastfeeding reduces the risk of infectious diseases in infancy. Pediatrics 2010, 126(1):e18-e25.

43. Howie PW, Forsyth JS, Ogston SA, Clark A, Florey CD: Protective effect of breast feeding against infection. BMJ 1990, 300(6716):11-16.

44. Wright CM, Parkinson K, Scott J: Breast-feeding in a UK urban context: who breast-feeds, for how long and does it matter? Public Health Nutr 2006, 9(6):686-691.

45. Palit A, Batabyal P, Kanungo S, Sur D: In-house contamination of potable water in urban slum of Kolkata, India: a possible transmission route of diarrhea. Water Sci Technol 2012, 66(2):299-303.

46. Esrey SA, Potash JB, Roberts L, Shiff C: Effects of improved water supply and sanitation on ascariasis, diarrhoea, dracunculiasis, hookworm infection, schistosomiasis, and trachoma. Bull World Health Organ 1991 69(5):609-621.

47. van der Hoek W, Konradsen F, Ensink JH, Mudasser M, Jensen PK: Irrigation water as a source of drinking water: is safe use possible? Trop Med Int Health 2001, 6(1):46-54.

doi:10.1186/1471-2458-13-87

Cite this article as: Sarkar et al:: Burden of childhood diseases and malnutrition in a semi-urban slum in southern India. BMC Public Health 2013 13:87.

\section{Submit your next manuscript to BioMed Central and take full advantage of:}

- Convenient online submission

- Thorough peer review

- No space constraints or color figure charges

- Immediate publication on acceptance

- Inclusion in PubMed, CAS, Scopus and Google Scholar

- Research which is freely available for redistribution 